\title{
Assaulting alternative medicine: worthwhile or witch hunt?
}

We made a mistake when editing this Observations article by Ray Moynihan (BMJ 2012;344:e1075, doi:10.1136/bmj.e1075). In the penultimate paragraph, the third sentence should have made clear that Steve Hambleton was referring to the Australian campaign to remove alternative medicine from university courses rather than the issue of alternative medicine in general. So the sentence should have ended: “. . . one person who has withdrawn his initial support is the president of the Australian Medical Association, Steve Hambleton, who believes that the campaign's pitch has become 'much fuzzier and less clear.'” The print version of this article is correct.

Cite this as: BMJ 2012;344:e1393

๑ BMJ Publishing Group Ltd 2012 